MATEC Web of Conferences 45, 04008 (2016)

DOI: $10.1051 /$ matecconf/20164504008

C) Owned by the authors, published by EDP Sciences, 2016

\title{
The Influence Study of Ultrasonic honing parameters to workpiece surface
}

\section{temperature}

\author{
Zhang Xiaoqiang $^{1}$, Zhu Xijing ${ }^{1}$ and Cheng Linglong ${ }^{2}$ \\ ${ }^{1}$ School of Mechanical and Power Engineering, North University of China, Taiyuan, China \\ ${ }^{2}$ Shanxi Jincheng Anthracite Mining King Ding Mining and Machinery CO., LTD., Jincheng, China
}

\begin{abstract}
Ultrasonic vibration honing (UVH), a machine technology, has a lot of advantages. Lower grinding temperature is a significant character and is beneficial for both processing and workpiece surface. But the high temperature caused by big honing pressure becomes the main factor to produce workpiece heat damage in grinding zone. In various honing parameter combinations, the showing effect is different. Based on the thermodynamics classical theory, established the heat transfer equation for grinding zone, simplified the model and obtained the two-dimenssion temperature field expression for workpiece, then simulated the temperature changing trend in a variety of conditions. It is shown that the main temp is in a range of $700 \mathrm{~K}$ to $1200 \mathrm{~K}$. In addition, the variation is huge for every parameter. The study provides a theoretical basis for deeply seeking reasonable machining parameter and obtaining better workpiece quality.
\end{abstract}

\section{Introduction}

Ultrasonic vibration honing (UVH) is a fresh machining technology, especially in machining newly hard brittle materials, and has more widely and practical industrial market[1]. The process is a course that the ultrasonic wave is transformed to mechanical vibration firstly, and transmitted by designing device to honing oilstone, caused the oilstone vibrating in machining the workpiece. The method can promote the working efficiency and the products quality.

The grinding temperature field is a major studying branch, many scholars have devoted in theory analysis and experimental measurement. Jaeger, the first scholar who propose the moving heat source theory, has obtained temperature rising theory for bulk heat source, and put forward the rectangular heat source model[2]. Later, the shear heat source model is presented by Outwater based on Jaeger's theory, the distribution method of heat is defined that a part of energy is deliveried to workpiece and other to abrasive dust[3]. While, it is different for Hahn that major heat is come from the abrasive grit wear area[4]. N.Alagumurthi has studyed the heat generation in grinding process, and proved that the temperature developed at the surface of the workpiece has an important influence to the metal remover[5]. Ding Han promoted the grinding temperature model taken abrasive shape and distribution into consideration[6]. J.L.González-Santander studys the heat transfer in surface dry grinding, considering the linear heat flux along the contact zone between the wheel and the workpiece, the

This is an Open Access article distributed under the terms of the Creative Commons Attribution License 4.0, which permits unrestricted use distribution, and reproduction in any medium, provided the original work is properly cited. 
result showed that the analytical result is useful for the monitoring of the online grinding process[7]. Until now, the primary research on grinding temperature is to establish the model and analysis the effect, the report for the mechanism that how the grinding heat impact workpiece quality is rare.

In honing processing, the oilstones have the rotational and reciprocating axially motion meanwhile, and suffer the radial pressure by reason of rotation which can induce a lot of energy in honing zone[8]. When the energy rise to too high, the workpiece surface will be affected, such as burn. So it is indispensable to analysis the temperature in workpiece surface, choose a group reasonable parameter set, gain the better machining quality.

The purpose of this paper is to present the expression of the workpiece surface which consider the machining method and its character. Two-dimension thermal models are established which is indicated by a difference equation. To simulate the temperature changing trend, the reasonable workpiece and oilstone material are chosen.

\section{Honing zone temperature model}

\subsection{UVH Model}

The UVH gains widely employed and developed due to the advantages of lowly temperature, pulse nature, small cutting force and etc. UVH device mainly includes ultrasonic transducer, booster, bending vibration disk, flexible string and oilstone. Fig. 1 shows the fundamental principle movement. It can be seen obviously that the thermal damage is occurred in honing zone between the oilstone and workpiece. For further completing the honing mechanism, it has become a essential portion to research the temperature field and thermal

Based on the moving heat source theory, the three-dimensional temperature distribution in honing zone for the model is obtained, and is given by the following difference equation expressions[9]:

$$
\frac{\partial^{2} T}{\partial x^{2}}+\frac{\partial^{2} T}{\partial y^{2}}+\frac{\partial^{2} T}{\partial z^{2}}=\frac{1}{\alpha}\left(\frac{\partial T}{\partial t}-v_{e a} \frac{\partial T}{\partial x}\right)
$$

$$
\begin{aligned}
& v_{e a}=\sqrt{v^{2}+\left(v_{a}+v_{f}\right)^{2}} \\
& =\sqrt{(\pi d n)^{2}+\left(v_{a}+2 \pi A f \cos 2 \pi f t\right)^{2}}
\end{aligned}
$$

Where, $d$ is the workpiece inner diameter, $\alpha=\lambda / c \rho$ is the thermal diffusivity of workpiece, $\lambda$ is the thermal conductivity, $c$ is the specific heat capacity, $\rho$ is the liquid fluid density.

\subsection{Temperature filed model of grinding zone}

For honing system, the boundary conditions satisfies the following set of equations

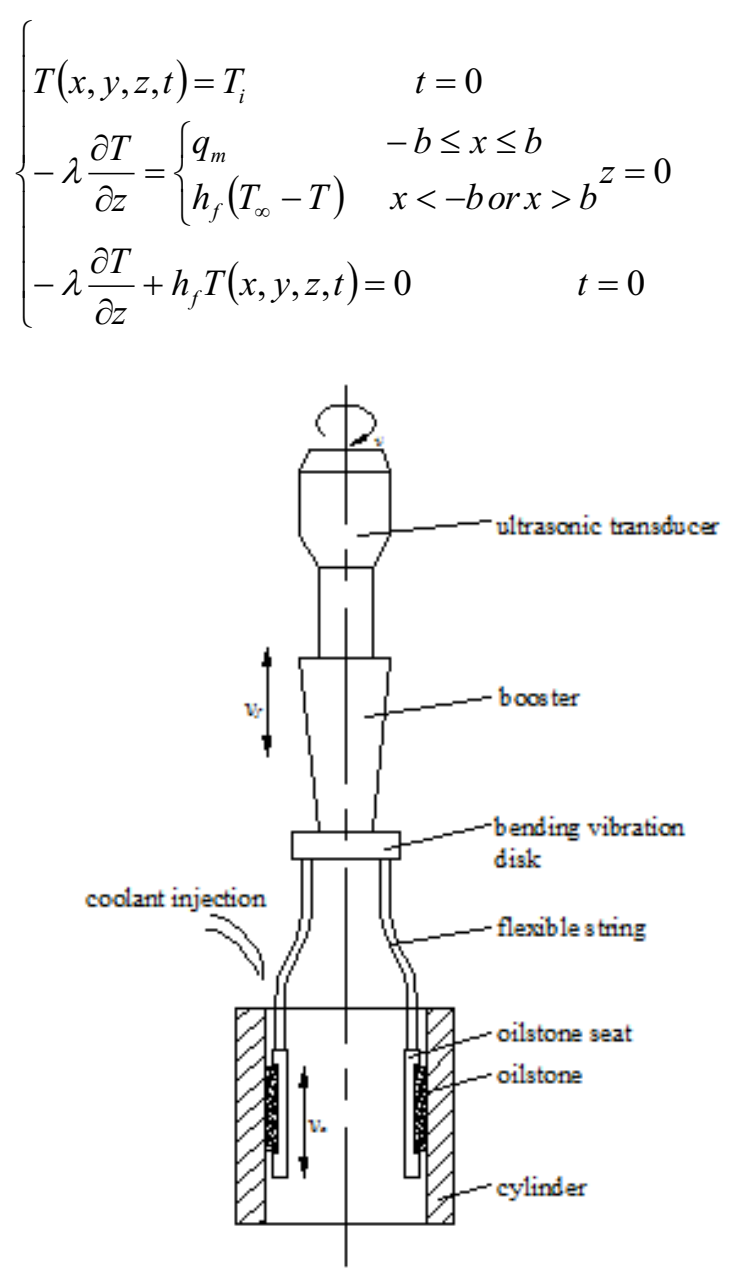

Figure 1. UVH system

Where, $b$ is the oilstone width, $h_{f}$ is the heat transfer coefficient, $T_{i}$ and $T_{\infty}$ are initial temperature and ambient temperature respectively and assumed $20^{\circ} \mathrm{C}$.

Then, for any point $\left(\mathrm{x}^{\prime}, \mathrm{y}^{\prime}, \mathrm{z}^{\prime}\right)$ in workpiece surface, the temperature field expression is equation (4). 


$$
\begin{gathered}
T=\frac{\alpha \cdot Q}{\lambda}\left\{\frac{2}{\left[4 \pi \alpha\left(t-t^{\prime}\right)\right]^{3 / 2}} \cdot \exp \left[-\frac{\left[x-x^{\prime}+v_{e a}\left(t-t^{\prime}\right)\right]^{2}+\left(y-y^{\prime}\right)^{2}+z^{2}}{4 \alpha\left(t-t^{\prime}\right)}\right]\right. \\
-\frac{h_{f}}{4 \pi \alpha \lambda\left(t-t^{\prime}\right)} \cdot \operatorname{erfc}\left[\frac{z}{\sqrt{4 \alpha\left(t-t^{\prime}\right)}}+\frac{h_{f}}{\lambda} \sqrt{\alpha\left(t-t^{\prime}\right)}\right] \cdot \operatorname{erfc}\left[-\frac{\left[x-x^{\prime}+v_{e a}\left(t-t^{\prime}\right)\right]^{2}+\left(y-y^{\prime}\right)^{2}+z^{2}}{4 \alpha\left(t-t^{\prime}\right)}\right] \\
\left.\cdot \exp \left[\frac{z h_{f}}{\lambda}+\alpha\left(\frac{h_{f}}{\lambda}\right)^{2}\left(t-t^{\prime}\right)\right]\right\}
\end{gathered}
$$

Table 1. UVH basic parameter

\begin{tabular}{ll}
\hline Parameter & Value \\
\hline Rotation speed of honing head $(\mathrm{r} / \mathrm{min})$ & $80 \sim 240$ \\
Honing pressure $(\mathrm{MPa})$ & $0.24 \sim 1.5$ \\
Ultrasonic amplitude $(\mu \mathrm{m})$ & $5 \sim 10$ \\
Reciprocating speed of honing oilstone $(\mathrm{m} / \mathrm{s})$ & $0.05 \sim 0.4$ \\
Ultrasonic frequency $(\mathrm{KHz})$ & $17 \sim 20$ \\
Wave pressure amplitude $(\mathrm{MPa})$ & $0.797 \sim 2.058$ \\
\hline
\end{tabular}

The honing model can be converted from three-dimension to two-dimension, shown in Fig.2.

For simplifying the analysis and calculation, the the 2D steady-state temperature distribution expression should be dimensionless and can be indicated $T(X, Z, \tau)=\frac{2 Q \alpha}{\lambda v_{e a}} \int_{0}^{\infty} d \tau\left[\exp \left(-\frac{Z^{2}}{4 \tau^{2}}\right)-K_{h}(Z, \tau)\right]$

$\cdot\left[\operatorname{erf}\left(\frac{X+L}{2 \tau}+\tau\right)-\operatorname{erf}\left(\frac{X-L}{2 \tau}+\tau\right)\right]$

Where,

$$
\begin{aligned}
& K_{h}(Z, \tau)=\pi H \tau \exp \left(H Z+H^{2} \tau^{2}\right) \cdot \operatorname{erfc}\left(\frac{Z}{2 \tau}+H \tau\right) \\
& X=\frac{v_{e a} x}{2 \alpha} ; \quad Z=\frac{v_{e a} z}{2 \alpha} ; L=\frac{v_{e a} b}{4 \alpha} ; H=\frac{2 \alpha h_{f}}{\lambda v_{e a}}
\end{aligned}
$$

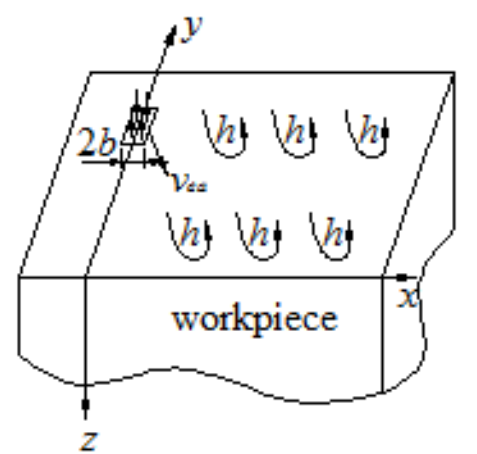

Figure 2. The two-dimension model of honing head $K=\sqrt{\frac{v_{e a}^{2} t}{4 \alpha}}$

\section{Honing parameters}

For UVH, there is a lot of relative parameters[10]. For analyzing the grinding temperature, it is computed to choose six important, shown in table 1.

The hard brittle material is the main workpiece quality, so the oilstone needs to choose available material. For the research, the workpiece chooses No.45 steel, and the oilstone chooses PCD. Table 2 shows the detailed material character.

Table 2. The character of materials

\begin{tabular}{llllll}
\hline & $\begin{array}{l}\text { Density } \\
(\mathrm{kg} / \mathrm{m} 3)\end{array}$ & $\begin{array}{l}\text { Young's } \\
\text { modulus }(\mathrm{GPa})\end{array}$ & $\begin{array}{l}\text { Possion's } \\
\text { ratio }\end{array}$ & $\begin{array}{l}\text { Thermal conductivity } \\
(\mathrm{W} /(\mathrm{m} \cdot \mathrm{K}))\end{array}$ & $\begin{array}{l}\text { Specific heat capacity } \\
\left(\mathrm{J} /\left(\mathrm{kg} \cdot{ }^{\circ} \mathrm{C}\right)\right)\end{array}$ \\
\hline Workpiece & 7.85 & 210 & 0.31 & 51.42 & 0.45 \\
Oiltone & 3.52 & 1050 & 0.18 & 136.16 & 6.17 \\
\hline
\end{tabular}




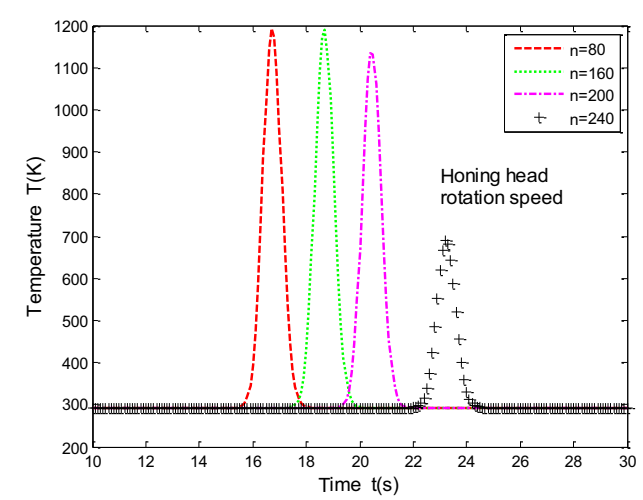

(a)

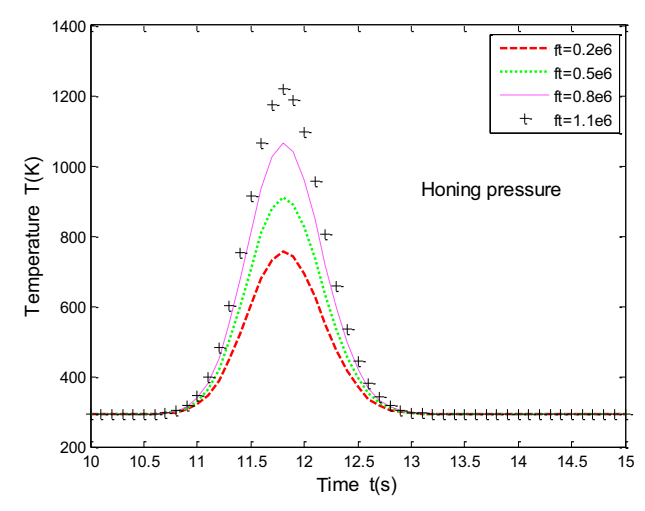

(c)

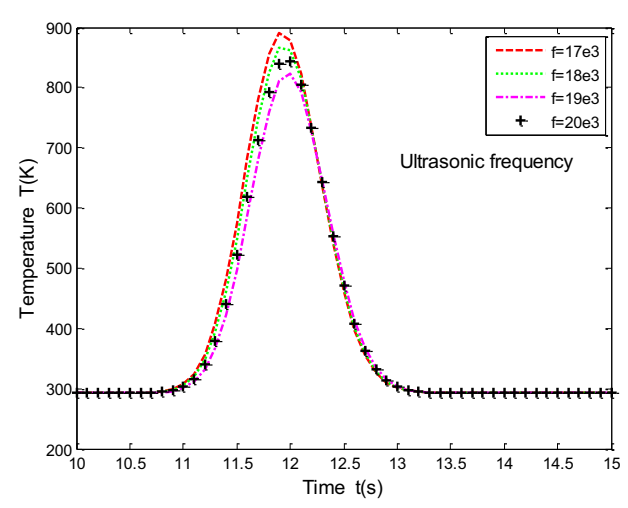

(e)

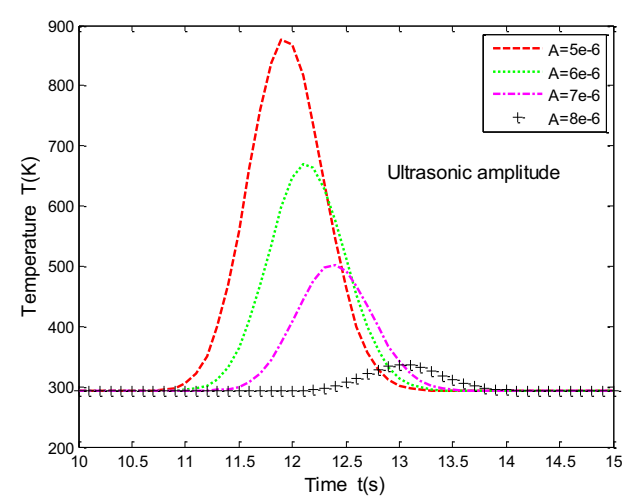

(b)

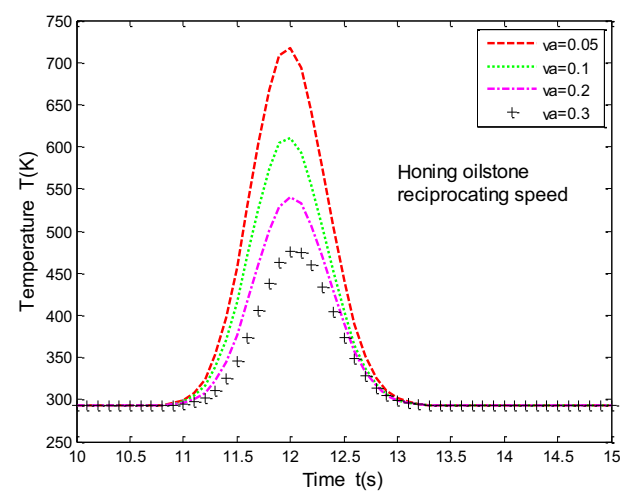

(d)

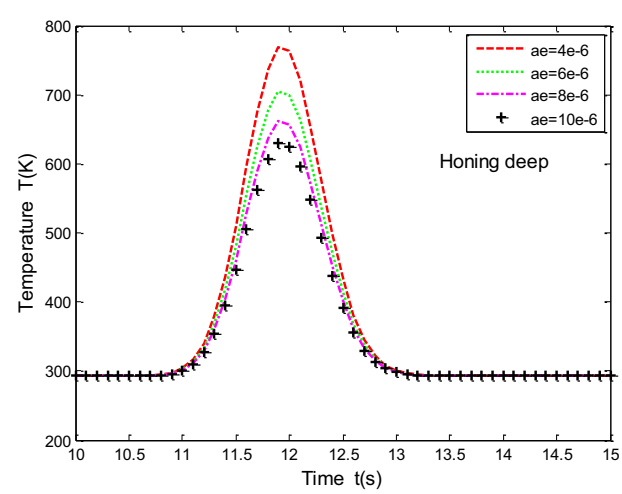

(f)

Figure 3. the temperature field of workpiece surface in different parameter

\section{Results and discussion}

Base on above analysis and choosing parameters, it can be obtained the temperature trend of workpiece surface, shown in Fig. 3.

From (a) $\sim(\mathrm{f})$, it is obviously shown that the trend is increase firstly, and then decrease. But for different parameters, the trend is various and the maximum temperature is different. For honing head rotational speed and ultrasonic amplitude, the time to reach the maximum is out of step, it is later by the speed enlargement. And the maximum temp will be felled suddenly when the speed reach a value above 200. But for ultrasonic amplitude, it desends uniformly and the rise and fall speed is also very gentle. In addition, it is shown that the peak temp is diverse for every parameter, but mainly located in the range $700 \mathrm{~K}$ to $1200 \mathrm{~K}$. Of course, the temp 
may be lower for some conditions from Fig.3(b)-(d), and the value is about $400 \mathrm{~K}$. The reason is that the heat is various for different parameter combinations, the behavior of the grinding heat is difference in honing zone. All the figure shows that the lowest temp isn't $0 \mathrm{~K}$, it can be explained that there is the frictional heating generating when the honing began. And the heat would be transfered quickly to the whole honing head device. Compared (c), (d) and (e), (f), it can be seen that the gradient is apparent, especially for honing pressure and reciprocating speed of honing oilstone.

Otherwise, from Fig.3(c) and (e), it can been seen that the temperature is enlarged by the honing pressure accretion, but reduced for others. And is firstly decreased and then increased for ultrasonic frequency from (e), but the change range is smaller. The time for every factor to reach the extrem value has a big difference. It is abot $17 \mathrm{~s}$ for rotational speed of honing head to attain, and the time interval for every value of rotational speed is or $2 \mathrm{~s}$. While it is about $12 \mathrm{~s}$ for others, and almost at the same time to reach. From time to explain, it is very short to machine for honing, and the total processing may be within 100 s, so the thermal transmission is also extremly short.

In summary, the workpiece surface temperature is contronlled with the limits of $700 \mathrm{~K}$ to $1200 \mathrm{~K}$. The study is basis for futher seeking avialable set to promote the conducts quality. For optimizing the honing process and obtaining better machin quality, the analyzing for temperature field in grinding zone is more significant.

\section{Summary}

The paper discusses the temperature field of workpiece surface in ultrasonic honing zone, based on the UVH mechanism and the moving heat source theory, established the temperature field expression for workpiece surface firstly, and then simulated the changing trend.

-The rotation speed of honing head and ultrasonic amplitude have more grivous impact for temperature field, not only for the maximum temp but the time to reach.
-In honing process, the temperature is basically increased at the begining and decended later, the gradient is very different for various parameter.

- The maximum temperature can reach about $700 \mathrm{~K}$ to $1200 \mathrm{~K}$ for all of parameter combinations, and the various machining parameter set will affect the value.

-The reasonable parameter set could be choosed for futher studying, $\mathrm{n}=80, \mathrm{~A}=6 \mu \mathrm{m}, \mathrm{ft}=0.5 \mathrm{MPa}, \mathrm{va}=0.1 \mathrm{~m} / \mathrm{s}$, $\mathrm{f}=19 \mathrm{KHz}, \mathrm{ae}=6 \mu \mathrm{m}$.

\section{Ackowledgements}

The authors would like to acknowledge the financial supported by the National Natural Science Foundation of China (No.51275490), the Natural Science Foundation of Shanxi Province (No.2013011024-5) and the 12th Graduate Students of Science and Technology Foundation of North University of China (No.20151214).

\section{References}

1. X. J. Zhu, H. J. Xu, A. L. Wang, et al. Research on the cutting principle of new non-conventional technology_Efficiency Ultrasonic Honing[J]. Key E M. 259-260: 640-643(2004).

2. J.C. Jaeger, Moving sources of heat and the temperature at sliding contacts.[J]. Proceedings of the Royal Society of New South Wales. 76:203(1942).

3. J. O. Outwater, Shaw M C. Surface temperature in grinding Trans ASME. 76:203(1952).

4. R. S. Hahn On the nature of the grinding process $[\mathrm{J}]$. Proceedings 3rd Machine Tool Design and Research Conference. 1:129-154(1962).

5. N. Alagumurthi, K. Palaniradja, V. Soundararajan. Heat generation and heat transfer in cylindrical grinding process-a numerical study $[\mathrm{J}]$. Int $\mathrm{J} \mathrm{Adv}$ Manuf Technol. 34:474-482(2007).

6. Dahu Zhu, Beizhi Li, Han Ding. An improved grinding temperature model considering grain geometry and distribution [J]. Int $\mathrm{J} \mathrm{Adv}$ Manuf Technol. 67:1393 -1406 (2013).

7. J.L.González-Santander. Analytic solution for 
maximum temperature during cut in and cut out in surface dry grinding [J]. Applied Mathematical Modelling. 10:1-12. (2015).

8. Zhu Xi Jing, Guo Ce, Wang Jian Qing. The pressure field radiated by cavitation bubble in the grinding area of power ultrasonic honing [J]. Adv Mat Res. 1027:44-47 (2014).

9. N. R. Des Ruisseaux, R. D. Zerkle. Temperature in semi-infinite and cylindrical bodies subjected to moving heat sources and surface cooling [J]. Journal of Heat Transfer. 92(3): 456-464(1970).

10. Guodong Liu, Xijing Zhu, Ce Guo. Research on modelling and simulation of cavitation sound field in the grinding zone of the power ultrasonic honing [J]. ACTA ACUSTICA. 38(6): 663-668(2013). 